\title{
Comparative Toxicity of Certain Acaricides against Tetranychus urticae Koch and their Side Effects on Phytoseiulus persimilis A.-H. (Acari: Tetranychidae: Phytoseiidae) \\ Hala R. Abdel-Rahman ${ }^{1}$ and M. M. Ahmed ${ }^{2}$ \\ ${ }^{1}$ Dept. Eco. Entomol. \& Pesticides, Fac. Agric. Cairo Univ., Egypt \\ ${ }^{2}$ Dept. Zool. \& Agric. Nematol., Fac. Agric. Cairo Univ., Egypt
}

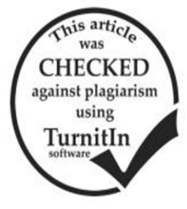

\begin{abstract}
The acaricidal activity using the recommended concentrations of the novel compound cyflumetofen $24 \% \mathrm{SC}$ as compared with bifenazate $48 \%$ SC and abamectine $1.8 \%$ EC was determined against the two-spotted spider mite, Tetranychus urticae Koch under greenhouse conditions at Faculty of Agriculture, Cairo University during 2017-2018. Their side effect on the predatory phytoseiid mite, Phytoseiulus persimilis Athias-Henriot was also investigated. Average number of mite mortality in the two seasons showed that abamectin was more toxic to predatory mite than other tested acaricides, while cyflumetofen was more toxic to spider mites T. urticae and followed by abamectin and bifenazate. Field trials proved that cyflumetofen was not as harmful as other compounds. Therefore, life-table parameters of both $T$. urticae and P. persimilis treated with $\mathrm{LC}_{50}$ of cyflumetofen were investigated in laboratory to know more knowledge about the population growth of mite pest and its natural enemy under stressful of treatment. Cyflumetofen prolonged the mean generation time, doubling time while it decreased fecundity as represented by female proportion in the generation, net reproductive rate, intrinsic rate of increase, finite rate of increase and gross reproductive rate of both mite species. Cyflumetofen showed considerable negative effects on T. urticae life-tables but it had moderate or low effects on P. persimilis. It is recommended to use the novel acaricide, cyflumetofen in IPM programs of plants feeding spider mites.
\end{abstract}

Keywords: Tetranychus urticae, Phytoseiulus persimilis, acaricides, toxicity, mite mortality, life table parameters

\section{INTRODUCTION}

Misuse of synthetic chemical pesticides had many negative effects such as groundwater contamination, human health threats and outbreaks of secondary pests (AbdelRahman and Fouly, 2001; Isman et al., 2011; Tirello et al., 2012). Chemical control should be applied when the pest population exceeds the economic injury threshold. Although this principle is designed to minimize pesticide use, sometimes the number of chemical applications can increase in an IPM program; however, under such conditions the pesticides applied ideally are selective pesticides, meaning they suppress pest populations without disrupting the activity of natural enemies. (Hoy, 2011). In other words, the main objective of control program is to kill the pest but not the beneficial organisms. Pesticides can be intrinsically selective, in that their chemistry makes them more toxic to pests than to beneficial species. Unfortunately, these products are less often available.

The two-spotted spider mite, Tetranychus urticae Koch (Tetranychidae), is a widespread and common mite pest of many plant species in greenhouses and open fields. This mite pest frequently reaches the economic injury level on over 150 host plant species worldwide (Zhang, 2003 and Ramasubramanian et al., 2005). Although, the importance of this mite is not only due to its direct damage but also due to indirect damage to plants which causes declines in photosynthesis and transpiration (Zhang, 2003). Further, when this mite begins to feed on a plant, they produce webbing that can protect its eggs and developmental stages from acaricide effects (Brandenburg and Kennedy, 1987).

The chemical pesticides have been widely used in suppressing the mite populations but they are hazardous to human and domestic animals. Indiscriminate use of chemical pesticides may however result in adverse effects such as resistance and resurgence in secondary pests (Ramasubramanian et al., 2005; Isman et al., 2011; Tirello et al., 2012). Pesticide resistance, the high cost of pesticides and loss of production have raised interest by growers to introduce predatory phytoseiid mites to manage the two-spotted spider mites and reduce their need for acaricide applications (Hassan, 1992 and Sabelis, 1981 and 1985).

The family Phytoseiidae is the most important family of acarine predators of plant pest mites (Helle and Sabelis, 1985; Sabelis 1985 and 1991 and McMurtry and Croft 1997). Relatively little is known about the biology of many of the approximately more than 2000 named phytoseiid species, because they are not found on agricultural crops. Some phytoseiids are found on crops in a single country, but some premier species are used in integrated mite management (IMM) programs in multiple countries. Phytoseiulus persimilis Athias-Henriot is one of the most important predators of spider mites, especially on protected crops (Irigari et al., 2007 and Tello et al., 2009). This species is an obligatory predator of tetranychid mites and reared commercially feeding on its natural hosts, Tetranychus spp. such as $T$. cinnabarinus and $T$. urticae using bean plants (Samsøe-Petersen, 1983; Zhang and Sanderson, 1990 and Nadimi et al., 2008). Despite the success of $P$. persimilis in reducing populations of $T$. urticae, acaricide applications may still necessary due to limitations associated with the effectiveness of $P$. persimilis introductions (Hassan, 1992 and Poletti et al., 2007).

In our present study, we aimed to evaluate the acaricidal activities of the novel acaricide cyflumetofen as compared with bifenazate and abamectin against all motile stages of T. urticae under greenhouse conditions. Also, experiments were done to determine their side effects on the predatory phytoseiid mite $P$. persimilis, which is widely used in IPM programs of spider mites especially in greenhouses. Moreover, laboratory experiments using LC50 of cyflumetofen, which achieved the highest efficiency against spider mites in greenhouse, were done to determine its latent effects on the life-table parameters of both spider mite $T$. urticae and its biological control agent $P$. persimilis just to understand the forthcoming information about the successive generations and their population growth. 


\section{MATERIALS AND METHODS}

\section{Mite Collection}

Mite individuals of $T$. urticae as well as the predatory mite species $P$. persimilis were collected from leaves of bean plants Phaseolus vulgaris L. growing in the Acarology greenhouse, Department of Zoology and Agricultural Nematology, Faculty of Agriculture, Cairo University, Egypt in summer 2017. Spider mite individuals were transferred to plastic pots (20 $\mathrm{cm}$ in diameter) containing bean plants to maintain a pure culture for further studies.

A pure colony of $P$. persimilis, was provided with spider mites as food source and kept in an incubator at $26 \pm$ $1 \mathrm{oC}$ and $70 \pm 5 \% \mathrm{RH}$. Newly deposited eggs of the predatory mite were collected daily for ten days and transferred to new cultures in order to get a surplus amount of mites and used in both toxicological and biological studies.

\section{Acaricides used}

Abamectin (vertemic 1.8\% EC): application rate 40ml/100L Chemical name: $80 \%$ avermectin B1a (22,23dihydroavermectin B1a: $\mathrm{C} 48 \mathrm{H} 72 \mathrm{O} 14)$ and $20 \%$ avermectin B1b (22,23-dihydroavermectin B1b: C47H70O14).

Bifenazate (acramite 48\% SC): application rate of $65 \mathrm{ml} / 100 \mathrm{~L}$

Chemical name: hydrazine carboxylic acid, 2-(4methoxy- [1,1 '-biphenylJ-3-yl) 1-methylethyl ester

Cyflumetofen (danisaraba 24\% SC): application rate $30 \mathrm{ml} / 100 \mathrm{~L}$. This compound is a novel benzoyl acetonitrile acaricide developed by Otsuka AgriTechno Co., Ltd.

Chemical name: 2-methoxyethyl (RS)-2-(4-tert-butylphenyl)2-cyano-3-oxo-3-( $\alpha, \alpha, \alpha$-trifluoro-o-tolyl) propionate

An experiment was conducted using the recommended concentration of three acaricides, cyflumetofen $24 \% \mathrm{SC}$, bifenazate $48 \% \mathrm{SC}$ and abamectin $1.8 \%$ EC (as mentioned before) against spider mites infesting bean plants growing under greenhouse conditions for two successive seasons 2017 and 2018.

\section{Experimental procedure:}

Soil of the greenhouse was well prepared before the plantation of bean seeds. The experimental area was divided into four plots (treatments) each of which containing 10 plants. The first three plots were sprayed with the recommended concentration of one of the three tested acaricides, while the fourth one was sprayed with water and used as a check. A manual compressor sprayer (20 liters capacity) was used for acaricide applications. Each treatment was replicated four times according to a complete randomized block design. Artificial infestation was conducted by individuals of spider mites $T$. urticae 45 days after seed germination.

The same technique was followed in similar plots infested with spider mites and containing the natural bioagent, $P$. persimilis and that just to configure the side toxicity effect of these acaricide to the predatory mite, which used for biological control purposes and lives in the same environment during control applications. In all cases, plant seedlings were left for 15 days for mite population increase.

Samples of 40 leaves were randomly collected from each treatment, just before spraying and then after 3, 6, 9 and 14 days afterwards. Leaf samples were kept in perforated polyethylene bags, tightly closed with rubber bands, kept in an ice box and then transferred to the laboratory for examination using a stereomicroscope. Alive moving stages of $T$. urticae and $P$. persimilis were recorded. Statistical analysis

Experiments were arranged in a completely randomized design where data were analyzed using one-way ANOVA. Means of alive mites were compared using Duncan's Multiple Range Test (CoStat program, 1990). Reduction percentages in populations of the two tested mite species $T$. urticae and $P$. persimilis were calculated and then corrected according to Henderson and Tilton's formula (1955).

\section{Experiments of life-table parameters \\ Preparation of $\mathrm{LC}_{50}$ of cyflumetofen $24 \%$ SC}

Five leaf discs ( $2 \mathrm{~cm}$ diameter) of fresh leaves of Acalypha wilkesiana L. were placed upside down on wet cotton pad in Phil dishes facing upper surface upward. The cotton bed was kept wet by soaking with water twice daily so that the discs remained fresh. Ten adults of each $T$. urticae and $P$. persimilis were transferred to each disc as replicate (50 adults for each concentration). Then it sprayed with $240,120,60,30$ and 15 ppm of cyflumetofen. Mites were maintained at suitable moisture and kept in incubator $26 \pm 2^{\circ} \mathrm{C}$ and $60 \pm 5 \%$ R.H. Mortality percentages were calculated for $T$. urticae and $P$. persimilis adults $24 \mathrm{hr}$ after spraying.

The $\mathrm{LC}_{50}$ values were estimated by applying probit analysis of Finney (1971) using mortality data which was corrected by Abbott's formula (1925).

$\mathrm{LC}_{50}$ for T. urticae $8.125 \mathrm{ppm}$

$\mathrm{LC}_{50}$ for $P$. persimilis $184.639 \mathrm{ppm}$

Tetranychus urticae culture

A pure culture of spider mites was collected from infested bean plants growing in the Acarology greenhouse, Cairo University. Adult females of spider mites were collected from the culture and kept on fresh leaves of castor bean, Ricinus communis and left for laying eggs. Plant leaves were placed on moist cotton pads in Petri dishes (15 cm in diameter) to kept leaf discs fresh, and to prevent mite individuals from escaping. The newly deposited eggs were collected daily for ten days and then divided into two groups of approximately 10 eggs each/arena. The first group was sprayed with $\mathrm{LC}_{50}$ of cyflumetofen $24 \%$ SC ( $8.129 \mathrm{ppm})$ by the aid of a manual hand sprayer (1 liter capacity), while the second group was sprayed with water and used as a check. Each group was replicated for five times. In daily controls the individuals that hatched and did not hatch from the eggs were recorded by using the control group as a reference. Counting hatchability continued until all untreated eggs hatched. All treatments were maintained in an incubator at $27 \pm 1{ }^{\circ} \mathrm{C}$ and $70 \pm 5 \%$ RH and photoperiod of 14:10 (D:L).

\section{Phytoseiulus persimilis culture}

A pure culture of $P$. persimilis was collected from bean plants infested with spider mites. Copulated adult females of $P$. persimilis were provided daily with a surplus amount of spider mites $T$. urticae as a prey and left to lay eggs on leaf discs of castor bean leaves. The same technique mentioned above was followed where treatments were sprayed with $\mathrm{LC}_{50}$ of cyflumetofen (184.639 ppm).

\section{Data analysis of life-table parameters}

Life table parameters of both $T$. urticae and $P$. persimilis, which were sprayed with the recommended 
concentration of cyflumetofen $24 \%$ SC as compared with those treated with water (control) were investigated. Duration of immature stages, mortality in developmental period and adults, sex ratio and total number of deposited eggs/females (fecundity) of $T$. urticae and $P$. persimilis were estimated daily and used for calculating the life-table parameters according to Birch (1948), Laing (1968) and then by using the Basic Computer Program of Abou-Setta et al. (1986). The intrinsic rate of natural increase, $r_{m}$ was estimated by the equation: $\Sigma e{ }^{r}{ }_{\mathrm{m}} L_{\mathrm{x}} M_{\mathrm{x}}=1$, where: $\mathrm{x}$ is the age in days, $L_{\mathrm{x}}$ the age-specific survival rate (proportion of females alive at age x) and $M_{\mathrm{x}}$ the oviposition rate at age $\mathrm{x}$ \{(age-specific oviposition) $\mathrm{x}$ (proportion of females) $\}$. The net reproductive rate $\left(R_{\mathrm{o}}\right)$ was given as $R_{\mathrm{o}}=\Sigma l_{\mathrm{x}} M_{\mathrm{x}}$ is the number of times as population will multiply per generation. The mean generation time in days $(T)$ was calculated as $T=\Sigma(x \cdot L x \cdot M x) / \Sigma(L x \cdot M x)$, then used as $\mathrm{T}=\ln R_{\mathrm{o}} / r_{\mathrm{m}}$. The proportion of females (number of females/total females+males) was used for calculating the $M_{\mathrm{x}}$ values as well as the intrinsic rate of increase $\left(r_{m}\right)$, the finite rate of increase $\left(e^{r m}=\lambda\right)$ is the number of times the population will multiply itself per unit of time as No. females/female/day. Doubling time $D T$ is the time required for a given population to double its number (in days) as well as gross reproductive rate $(G R R=\Sigma M x)$ measured as female eggs/female/generation.
The life-tables of both T. urticae and P. persimilis were prepared from data recorded daily on developmental time (egg to first egg laid), sex ratio, the number of deposited eggs, the fraction of eggs reached maturity, and the survival of females. Interval of one day was chosen as the age classes for constructing the life-tables.

\section{RESULTS AND DISCUSSION}

\section{Effect of tested acaricides on Tetranychus urticae}

In 2017, data in Table (1) clearly showed that there is a significant difference between the toxic effect of cyflumetofen on spider mites mortality and both bifenazate and abamectin just one day after treatment where these compounds reduced mite populations by an average of $95.88 \%, 79.51 \%$ and $76.84 \%$, respectively. Treated mite individuals started to overcome from chemical applications three days after spraying where mite mortality averages $94.12 \%, 54.46 \%$ and $68.83 \%$ for the mites treated with the same acaricides, respectively. At the end of experiment 14 days after spraying, cyflumetofen proved to be the most persistent compound where it caused mortality $82.54 \%$, and abamectin came second by $61.99 \%$ while bifenazate caused the least mortality rate by an average of $36.93 \%$ and all differences were significant (Table 1).

Table 1. Average No. of live Tetranychus urticae Koch treated and untreated with three acaricides infesting bean plants Phaseolus vulgaris during 2017 and 2018 under greenhouse conditions

\begin{tabular}{|c|c|c|c|c|c|c|c|c|c|c|c|}
\hline \multirow{3}{*}{ Year } & \multirow{3}{*}{$\begin{array}{c}\text { Time } \\
\text { after } \\
\text { treatment }\end{array}$} & \multicolumn{6}{|c|}{ Tested acaricides } & \multirow{3}{*}{ Control } & \multirow{3}{*}{ L.S.D } & \multirow{3}{*}{$\mathbf{F}$} & \multirow{3}{*}{$\begin{array}{c}P \leq \\
(0.05)\end{array}$} \\
\hline & & \multicolumn{2}{|c|}{ Cyflumetofen } & \multicolumn{2}{|c|}{ Bifenazate } & \multicolumn{2}{|c|}{ Abamectin } & & & & \\
\hline & & $\begin{array}{c}\text { Mean } \\
\text { No./Leaf }\end{array}$ & $\begin{array}{c}\text { Reduction } \\
\%\end{array}$ & $\begin{array}{c}\text { Mean } \\
\text { No./Leaf }\end{array}$ & $\begin{array}{c}\text { Reduction } \\
\%\end{array}$ & $\begin{array}{c}\text { Mean } \\
\text { No./Leaf }\end{array}$ & $\begin{array}{c}\text { Reduction } \\
\%\end{array}$ & & & & \\
\hline \multirow{6}{*}{2017} & Pre-treatment & 8.10 & - & 6.88 & - & 7.95 & - & 8.88 & & & \\
\hline & 1 day & $0.58^{\mathrm{b}}$ & 95.88 & $2.45^{\mathrm{a}}$ & 79.51 & $3.20^{\mathrm{a}}$ & 76.84 & 15.43 & 1.42 & 9.22 & ** \\
\hline & 3 days & $1.33^{\mathrm{b}}$ & 94.12 & $8.75^{\mathrm{a}}$ & 54.46 & $6.92^{\mathrm{ab}}$ & 68.83 & 24.80 & 5.79 & 4.57 & $*$ \\
\hline & 6 days & $4.95^{c}$ & 90.31 & $31.50^{\mathrm{a}}$ & 27.40 & $18.25^{\mathrm{b}}$ & 63.62 & 56.00 & 7.53 & 31.82 & $* * *$ \\
\hline & 9 days & $8.25^{\mathrm{b}}$ & 78.97 & $29.25^{\mathrm{a}}$ & 12.20 & $16.75^{\mathrm{b}}$ & 56.51 & 43.00 & 11.80 & 8.20 & $* *$ \\
\hline & 14 days & $11.25^{\mathrm{a}}$ & 53.46 & $18.25^{\mathrm{b}}$ & 11.10 & $13.25^{\mathrm{a}}$ & 44.18 & 26.50 & 8.73 & 1.74 & $*$ \\
\hline Mean & & $5.27^{\mathrm{c}}$ & 82.54 & $18.04^{\mathrm{a}}$ & 36.93 & $11.76^{\mathrm{b}}$ & 61.99 & 29.10 & 4.62 & 20.12 & $* *$ \\
\hline \multirow{6}{*}{2018} & Pre-treatment & 8.45 & -- & 7.70 & -- & 9.30 & -- & 9.48 & -- & -- & -- \\
\hline & 1 day & $0.80^{\mathrm{c}}$ & 96.01 & $2.38^{\mathrm{b}}$ & 86.98 & $4.28^{\mathrm{a}}$ & 80.61 & 22.50 & 1.26 & 19.62 & $* * *$ \\
\hline & 3 days & $5.00^{\mathrm{D}}$ & 89.85 & $9.25^{\mathrm{a}}$ & 79.40 & $12.0^{\mathrm{a}}$ & 77.51 & 55.25 & 3.64 & 9.58 & $* *$ \\
\hline & 6 days & $11.08^{\mathrm{b}}$ & 83.05 & $30.25^{\mathrm{a}}$ & 49.16 & $24.75^{\mathrm{a}}$ & 65.56 & 73.25 & 11.26 & 7.86 & $*$ \\
\hline & 9 days & $15.23^{\mathrm{b}}$ & 70.15 & $39.25^{\mathrm{a}}$ & 15.59 & $31.0^{\mathrm{a}}$ & 44.80 & 57.25 & 14.48 & 7.26 & $*$ \\
\hline & 14 days & $14.33^{\mathrm{b}}$ & 62.61 & $33.75^{\mathrm{a}}$ & 3.37 & $37.5^{\mathrm{D}}$ & 11.10 & 43.00 & 17.34 & 5.27 & $*$ \\
\hline Mean & & $9.28^{b}$ & 80.33 & $22.97^{\mathrm{a}}$ & 46.90 & $21.90^{\mathrm{a}}$ & 55.92 & 43.45 & 8.12 & 6.24 & $*$ \\
\hline
\end{tabular}

Means No. of mite individuals/leaf followed by the same letter in each row are not significantly different, Duncan Multiple Range Test (P $\leq 0.05)$ Mortality \% was corrected according to Henderson \& Tilton (1955)

In 2018, similar trend of acaricide's toxicity was observed where the highest rate of mortality in spider mite population was achieved by cyflumetofen where $96.01 \%$ of treated mites were killed $24 \mathrm{hr}$ after treatment. This percentage was significantly declined by using bifenazate and abamectin that caused $86.98 \%$ and $80.61 \%$ mortality, respectively (Table 1). At the end of experiments, cyflumetofen caused the highest total average of spider mite mortality and followed by abamectin and then bifenazate. The mite mortality was $80.33 \%, 55.92 \%$ and $46.90 \%$ in mites treated with the aforementioned acaricides as shown in Table 1, respectively.

From the previous results it can be concluded that the recommended concentration of cyflumetofen proved to be more toxic to spider mites $T$. urticae and followed by abamectin while bifenazate was the last in its acaricidal effect against mite pest. Similar results were obtained by Latheef and Hoffman (2014) who tested five pesticides against $T$. urticae and found that abamectin and bifenazate was ten times more toxic than dicofol. They arranged the tested compounds according to their toxicity level as abamectin $>$ bifenazate $>$ dicofol $>$ propargite $=$ spiromesfin . They declared that spider mites treated with acaricides will become hyperactive after approximately 3 hours and will cease feeding. Subsequently, their movements gradually decrease (paralysis) and mortality occurs after 3 to 7 days and this may explain why they have a higher initial kill or knock down effect against mite individuals.

\section{Effect of tested acaricides on Phytoseiulus persimilis}

Table (2) proved that there were no significant differences between the toxic action of the three tested acaricides, which were tested mainly against the 
phytophagous spider mites, on the non-target predatory mite $P$. persimilis even in 2017 or 2018. The initial kill of abamectin was the highest with $37.85 \%$, followed by bifenazate (30.33\%) and cyflumetofen $(30.30 \%), 24 \mathrm{hr}$ after treatment in 2017, respectively. These percentages sharply declined after 14 days to be $2.89 \%, 5.0 \%$ and $1.04 \%$ mortality for $P$. persimilis treated with the aforementioned miticides, respectively. Abamectin also caused a higher killing action in 2018 as compared with that in 2017 and recorded the highest rate of mortality among the tested compounds by an average of $45.96 \%$ mortality in $P$. persimilis populations and then declined gradually to only $8.98 \%$ at the end of experiments. Bifenazate occupied the second rank in its negative effect on the predatory mite where it killed $30.0 \%$ while cyflumetofen caused the lowest mortality of $23.14 \%$ one day after spray, respectively (Table 2). After 14 days from application, bifenazate and cyflumetofen caused only 11.21 and $1.90 \%$ mite mortality. These findings agree with Kim and Seo (2001) and Kim and Yoo (2002) who found that bifenazate had low mortality and no effect on fecundity and fertility of treated females of both phytoseiid species $P$. persimilis and Amblyseius womersleyi. Similarly, Irigaray and Zalom (2006) found that etoxazole and bifenazate didn't reduce adult longevity of the predatory phytoseiid mite Galendromus occidentalis (Nesbitt), but progeny were not produced.

Table 2. Avarage No. of the motile stages of the predatory mite, Phytoseiulus persimilis A.-H. treated and untreated with three acaricides on bean plants Phaseolus vulagaris during 2017 and 2018 under greenhouse condition.

\begin{tabular}{|c|c|c|c|c|c|c|c|c|c|c|c|}
\hline \multirow{3}{*}{ Year } & \multirow{3}{*}{$\begin{array}{c}\text { Time } \\
\text { after } \\
\text { treatment }\end{array}$} & \multicolumn{6}{|c|}{ Tested acaricides } & \multirow[b]{3}{*}{$\begin{array}{l}\text { Check } \\
\text { No./Leaf }\end{array}$} & \multirow{3}{*}{ L.S.D } & \multirow{3}{*}{$\mathbf{F}$} & \multirow{3}{*}{$\begin{array}{c}\mathrm{P} \leq \\
(\mathbf{0 . 0 5})\end{array}$} \\
\hline & & \multicolumn{2}{|c|}{ Cyflumetofen } & \multicolumn{2}{|c|}{ Bifenazate } & \multicolumn{2}{|c|}{ Abamectin } & & & & \\
\hline & & $\begin{array}{c}\text { Mean } \\
\text { No./Leaf }\end{array}$ & $\begin{array}{c}\text { Reduction } \\
\%\end{array}$ & $\begin{array}{c}\text { Mean } \\
\text { No./Leaf }\end{array}$ & $\begin{array}{c}\text { Reduction } \\
\%\end{array}$ & $\begin{array}{c}\text { Mean } \\
\text { No./Leaf }\end{array}$ & $\begin{array}{c}\text { Reduction } \\
\%\end{array}$ & & & & \\
\hline \multirow{6}{*}{2017} & Pre-treatment & 4.00 & - & 4.00 & - & 3.00 & - & 3.8 & -- & -- & -- \\
\hline & 1 day & $2.75^{\mathrm{a}}$ & 30.30 & $2.75^{\mathrm{a}}$ & 30.33 & $1.84^{\mathrm{b}}$ & 37.85 & 3.75 & 1.41 & 2.30 & $\mathrm{Ns}$ \\
\hline & 3 days & $4.25^{\mathrm{a}}$ & 19.25 & $3.20^{\mathrm{a}}$ & 27.62 & $2.20^{\mathrm{b}}$ & 32.44 & 4.20 & 2.06 & 3.28 & $\mathrm{Ns}$ \\
\hline & 6 days & $4.80^{\mathrm{a}}$ & 8.40 & $3.94^{\mathrm{a}}$ & 18.63 & $3.20^{\mathrm{b}}$ & 11.88 & 4.60 & 1.96 & 5.38 & Ns \\
\hline & 9 days & $4.60^{\mathrm{a}}$ & 8.90 & $4.25^{\mathrm{a}}$ & 15.89 & $3.40^{\mathrm{a}}$ & 10.28 & 4.80 & 2.53 & 0.90 & Ns \\
\hline & 14 days & $5.00^{\mathrm{a}}$ & 1.04 & $5.00^{\mathrm{a}}$ & 5.00 & $3.68^{\mathrm{a}}$ & 2.89 & 4.80 & 1.58 & 2.14 & $\mathrm{Ns}$ \\
\hline Mean & & $4.28^{\mathrm{a}}$ & 13.58 & $3.82^{\mathrm{a}}$ & 19.49 & $2.86^{\mathrm{a}}$ & 19.07 & 4.43 & 1.84 & 4.82 & Ns \\
\hline \multirow{6}{*}{2018} & Pre-treatment & 4.25 & -- & 4 & -- & 4.75 & -- & 5.25 & -- & -- & -- \\
\hline & 1 day & $2.80^{\mathrm{a}}$ & 23.14 & $2.40^{\mathrm{a}}$ & 30.00 & $2.20^{\mathrm{a}}$ & 45.96 & 4.50 & 1.70 & 0.29 & Ns \\
\hline & 3 days & $3.20^{\mathrm{a}}$ & 17.65 & $2.68^{\mathrm{a}}$ & 26.72 & $2.68^{\mathrm{a}}$ & 38.29 & 4.80 & 2.39 & 1.58 & Ns \\
\hline & 6 days & $4.40^{\mathrm{a}}$ & 12.33 & $3.60^{\mathrm{a}}$ & 23.79 & $4.60^{\mathrm{a}}$ & 18.00 & 6.20 & 3.32 & 0.8 & Ns \\
\hline & 9 days & $4.60^{\mathrm{a}}$ & 5.29 & $3.88^{\mathrm{a}}$ & 15.13 & $4.82^{\mathrm{a}}$ & 11.21 & 6.00 & 4.61 & 0.73 & Ns \\
\hline & 14 days & $5.40^{\mathrm{a}}$ & 1.90 & $4.60^{\mathrm{a}}$ & 11.21 & $5.60^{\mathrm{a}}$ & 8.98 & 6.80 & 3.28 & 1.08 & $\mathrm{Ns}$ \\
\hline$\overline{\text { Mean }}$ & & $4.08^{a}$ & 12.06 & $3.71^{\mathrm{a}}$ & 21.37 & $3.98^{\mathrm{a}}$ & 24.48 & 5.66 & 1.64 & 1.24 & Ns \\
\hline
\end{tabular}

Means No. of mite individuals/leaf followed by the same letter in each row are not significantly different, Ns = not significant, Duncan Multiple Range Test $(\mathrm{P} \leq \mathbf{0 . 0 5}) \quad$ Mortality \% was corrected according to Henderson \& Tilton (1955)

Comparative analysis of mite mortality of both spider mite and its predator, tested miticides showed a higher acaricidal activity against the target mite pest. Therefore, it can be concluded that $P$. persimilis was not as sensitive as spider mites to acaricide applications. Therefore, the predatory mite individuals, which survived after treatments, can soon recover and build up their population. These results proved that tested acaricides have a kind of selectivity against the mite pest and moderate or low side effect on the nontarget bio-agent $P$. persimilis as shown in Tables (1-2). Irigaray and Zalom (2006) found that acequinocyl, etoxazole and spiromesifen didn't harm the predatory phytoseiid mite G. occidentalis where they didn't reduce its female longevity but they significantly reduced its fecundity. They also found that mite females treated with bifenazate stopped laying eggs. Dekeysr et al., (1996) and Dekeysr (2005) contradictory found that bifenazate to be harmless to adult females of $G$. occidentalis. Also, Rhodes et al. (2006) reviewed that bifenazate can be used in IPM programs of spider mites especially with the use of $P$. persimilis. These results agree with the findings obtained by Nadimi et al., (2011), AbdeMageed et al., (2013), and Halloum and Qerhaili (2013). On the other hand, Nadimi et al. (2008) used 25\%, 50\% and $100 \%$ of the recommended concentration of abamectin in the open field to control spider mites and they found that all these concentrations were harmful to $P$. persimilis especially to its reproduction and survival rates. Therefore, they stated that abamectin is not compatible in IMM programs when $P$. persimilis is involved.

In conclusion, the activity of different acaricides may depend mainly on the mite species as well as acaricides used.

Effect of tested acaricides $\left(\mathrm{LC}_{50}\right)$ on life-table parameters of Tetranychus urticae and Phytoseiulus persimilis

The obtained results in the laboratory showed that $92 \%$ of untreated spider mites, $T$. urticae succeeded to reach adulthood, while only $78 \%$ from mites, which were subjected to $\mathrm{LC}_{50}$ of cyflumetofen passed to adulthood as represented by $L x$ values (Fig. 1). These values were $94 \%$ and $84 \%$ for $P$. persimilis untreated and treated individuals that reached maturity, respectively. The present observations proved again that the tested compound is a selective acaricide against the spider mite but not to its natural enemy. In other words, Fig. (1) illustrates that $L x$ values gradually decreased during the oviposition period for both spider mite and its predatory mite.

It was also found that chemical application using $\mathrm{LC}_{50}$ of cyflumetofen had insignificant effect on the sex ratio where cyflumetofen caused a female proportion of an average of $0.54-0.52$ for untreated and treated T. urticae, while it was $0.62-0.56$ for $P$. persimilis, respectively (Table 3). Contradictory, Li et al., (2006) found that clofentezine negatively affected the sex ratio of $T$. viennsis Zacher where female proportion significantly decreased by acaricidal application. The same negative effect was observed by Marcic (2003) for flufentezine and hexythiazox who 
suggested that perhaps this may due to the development of non-differentiated reproductive cells in mother mites treated with acaricides which is considered to be the most intensive at the deutonymphal stage. Therefore, it can be concluded that the variation of sex ratio in different exposure regimes in this study provided circumstantial evidence for the hypothesis that a female should shift her sex ratio towards the production of males when facing stressful environments. In general, acaricides that retard or inhibit mite development seem to disturb this process and cause decrease in the fertility of mother mites, which survived after treatment. Moreover, Hayashi et al., (2013) demonstrated that $\mathrm{LC}_{50}$ of cyflumetofen inhibited metochondria complex II in mites and it was more effective on spider mites such as citrus red spider mite, Panonychus citri (McGregor) and T. urticae than on non-target species. They recommended the use of cyflumetofen in IMM programs especially in greenhouses.

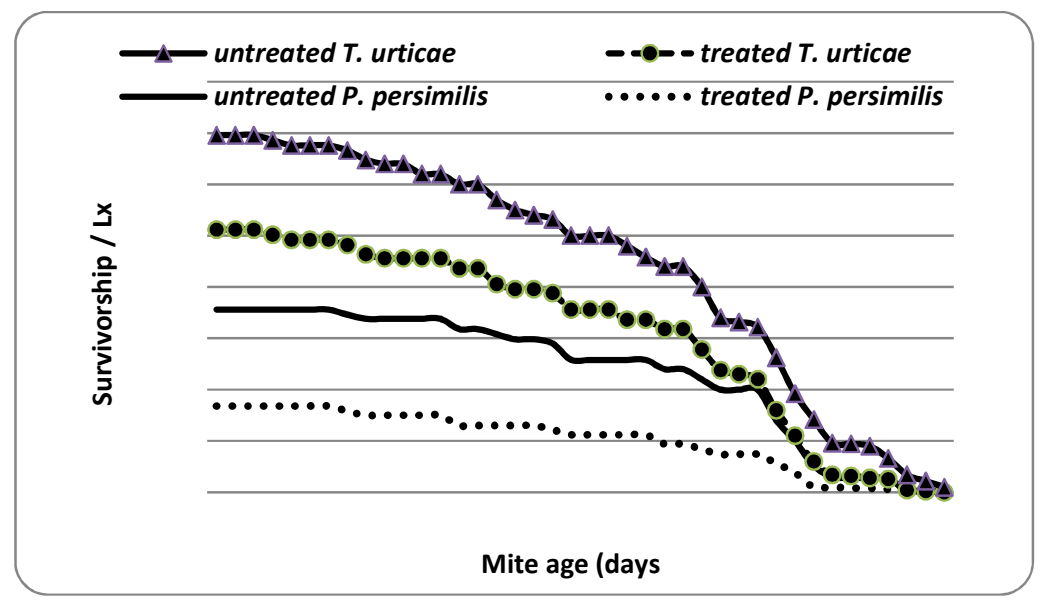

Fig. 1. Age-specific survival (Lx) of un-treated and treated Tetranychus urticae and Phytoseiulus persimilis with $\mathrm{LC}_{50}$ of cyflumetofen under laboratory conditions of $27^{\circ} \mathrm{C}$ and $70 \% \mathrm{RH}$

The mean generation time $(T)$ was obviously affected by chemical application as shown in Table (3). Therefore, $\mathrm{LC}_{50}$ of cyflumetofen application prolonged $T$ time of T. urticae from 17.54 days for untreated mites to 21.86 days for treated ones, respectively. Similarly, Li et al., (2006) found that clofentezine also delayed T. viennsis development and prolonged $T$ time for 2.5 days in comparison with untreated individuals. Contradictory, chemical application neither prolonged nor shortened $T$ time of $P$. persimilis where it was 21.99 and 22.84 days in untreated and treated mites, respectively (Table 3 ).

Generally, chemical application reduced the net reproductive rate $R_{o}$ of both mite species, where $\mathrm{LC}_{50}$ of cyflumetofen fortunately showed an adverse effect on fecundity females/female) to spider mites $T$. urticae where $R_{o}$ was 44.10 in control group and then sharply declined to 24.11 female eggs/female/generation in treated group, respectively. That means, $\mathrm{LC}_{50}$ of cyflumetofen reduced the reproductive rate of spider mite by almost $50 \%$ in the first generation after treatment as shown in age-specific fecundity curve (Fig. 2). These findings agree with those obtained by Marcic (2003 and 2007) and Li et al., (2006) who showed that clofentezine and spirodiclofen highly reduced the net reproductive rates of spider mites but when they treated mite individuals with sublethal concentrations they found that $R_{o}$ increased. Marcic (2003) found that $R_{o}$ of untreated spider mites was about 2.6 times more than treated ones.

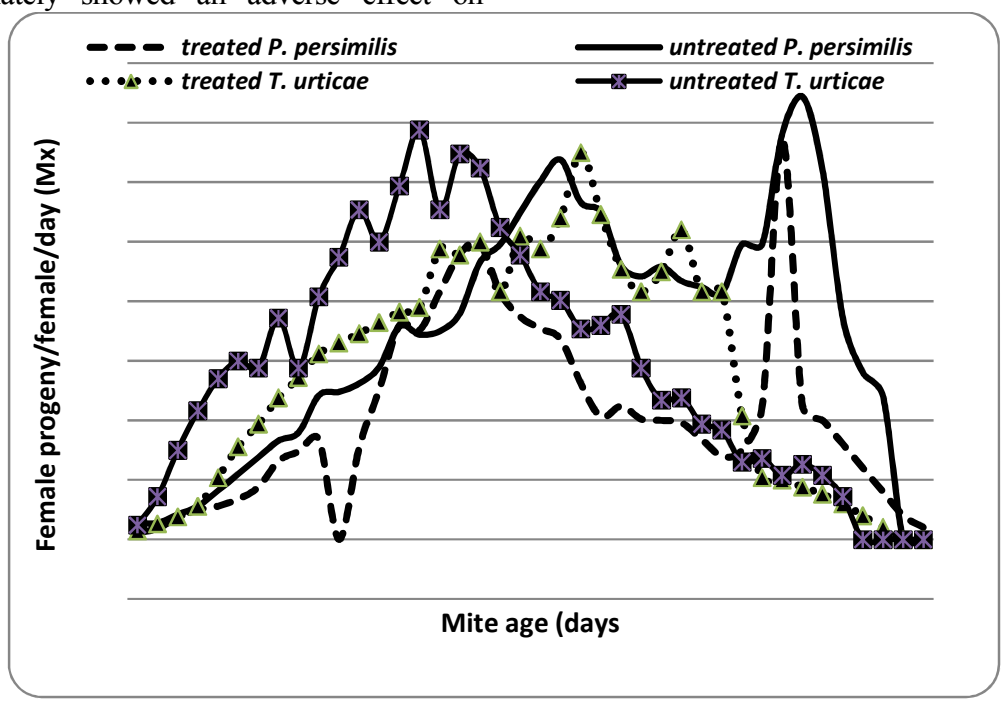

Fig. 2. Age-specific fecundity (Mx) of un-treated and treated Tetranychus urticae and Phytoseiulus persimilis with $\mathrm{LC}_{50}$ of cyflumetofen under laboratory conditions of $27^{\circ} \mathrm{C}$ and $70 \% \mathrm{RH}$ 
Table 3. Life table parameters of both untreated Tertanychus urticae and Phytoseiulus persimilis and treated with cyflumetofen $24 \%$ SC under laboratory conditions of $27^{\circ} \mathrm{C}$ and $70 \%$ RH

\begin{tabular}{|c|c|c|c|c|}
\hline \multirow{3}{*}{$\begin{array}{l}\text { Life table } \\
\text { parameters }\end{array}$} & \multicolumn{4}{|c|}{ Mite species } \\
\hline & \multicolumn{2}{|c|}{$\begin{array}{c}\text { Tetranychus } \\
\text { urticae }\end{array}$} & \multicolumn{2}{|c|}{$\begin{array}{c}\text { Phytoseiulus } \\
\text { persimilis }\end{array}$} \\
\hline & 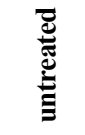 & 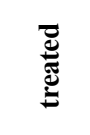 & 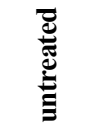 & 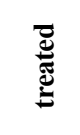 \\
\hline No. mite individuals & 48 & 41 & 50 & 46 \\
\hline Hatchability \% & 96 & 82 & 100 & 92 \\
\hline Female proportion $(\mathrm{No} .+/ q+\hat{\prime})$ & 0.54 & 0.52 & 0.62 & 0.56 \\
\hline Mean generation time $T$ & 17.54 & 21.86 & 22.84 & 21.99 \\
\hline Net reproductive rate $R_{o}$ & 44.10 & 24.11 & 28.12 & 24.82 \\
\hline Intrinsic rate of increase $\mathrm{rm}$ & 0.216 & 0.145 & 0.173 & 0.161 \\
\hline Finite rate of increase $e^{r m}(\lambda)$ & 1.24 & 1.15 & 1.18 & 1.14 \\
\hline Doubling time $D T$ & 1.39 & 2.13 & 1.79 & 2.36 \\
\hline Growth reproduction $G R R$ & 58.77 & 54.11 & 36.07 & 32.17 \\
\hline
\end{tabular}

On the other hand, $\mathrm{LC}_{50}$ of cyflumetofen didn't show this negative effect on fecundity of the predatory mite $P$. persimilis where $R_{o}$ was 28.12 and slightly decreased to 24.88 female eggs/female/generation for untreated and treated mite individuals, respectively (Table 3 ). These results contradicted with findings of Nadimi et al. (2008) who found that abamectin significantly decreased reproduction and fertility of $P$. persimilis. Zhang and Sanderson (1991) previously found that abamectin retarded egg production of $P$. persimilis and they believed that it may be due to the decrease in mite's mobility and thus consuming fewer preys. Similarly, Kim et al. (2005) found that abamectin reduced fecundity of Amblyseius cucumeris (Oudemans) from 130 eggs/female to only 6 eggs/female in control and treatment, respectively.

The intrinsic rate of natural increase $\left(r_{m}\right)$ is the rate of increase of an insect or mite species under specific physical conditions, as described by Birch (1948). The present data showed that $\mathrm{LC}_{50}$ of cyflumetofen application obviously reduced $r_{m}$ by approximately $50 \%$ where it was 0.216 female offspring/female (female ${ }^{-1} \mathrm{day}^{-1}$ ) in T. urticae control group and then declined to 0.145 after treatment as shown in Table (3). This gab was not observed between untreated and treated individuals of $P$. persimilis with cyflumetofen. The intrinsic rate of increase was 0.173 female/female in untreated mites and reduced by the application to 0.161 (Table 3). These results are supported by Marcic (2003) who found tha $r_{m}$ of untreated $T$. urticae was significantly bigger than mite treated with clofentezine where it was 0.242 and declined to 0.215 female/female, respectively.

Concerning the finite rate of increase $\left(e^{r m}(\lambda)\right)$ which is the number of times the population will multiply itself per unit of time and measured in females/female/day or the expected numbers of new females which would added daily to the population $\left(\right.$ day $\left.^{-1}\right)$. The present results showed that the finite rate of increase of $T$. urticae, which was subjected to $\mathrm{LC}_{50}$ of cyflumetofen, was reduced by $7.25 \%$ from 1.24 to +1.15 eggs/female/day $\left(\right.$ day $\left.^{-1}\right)$. These values were $3.38 \%$ from 1.18 and 1.14 eggs/female/day for untreated and treated $P$. persimilis, respectively (Table 3 ). Therefore, cyflumetofen was more effective on spider mites than on predatory mite. These results agree with those obtained by Marcic (2007) who found that spirodiclofen significantly reduced the rate of natural increase and finite rate of increase of spider mites. Similarly, Ghsemzadeh and Qureshi (2018) demonstrated that fenpyroximate and thiacloprid negatively influenced the biological parameters $\left(r_{m}\right.$ and $\left.e^{r m}\right)$ of the phytoseiid mite Amblyseius swirskii Athis-Henriot.

The present results also showed that $\mathrm{LC}_{50}$ of cyflumetofen prolonged $D T$ time, the time required for a population to double itself, of T. urticae from 1.39 to 2.13 days and from 1.79 to 2.36 days for $P$. persimilis, respectively. These results agree with those obtained by Marcic (2007) who found that spirodiclofen significantly extended the doubling time of $T$. urticae. Moreover, Ghasemzadeh and Qureshi (2018) noticed that fenpyroximate and thiaclopride extended $D T$ time of $A$. swirskii as compared with untreated individuals.

Gross reproduction rate $G R R\left(\sum M x\right)$ also was affected by the acaricidal application where it was 58.77 and declined to 54.11 offspring for untreated and treated spider mites with $\mathrm{LC}_{50}$ of cyflumetofen. While $G R R$ of $P$. persimilis was 36.07 and declined to 32.17 offspring in untreated and treated individuals, respectively (Table 3 ). The present observations are supported by the findings of Li et al., (2006) who found that clofentezine retarded GRR of spider mite, T. viennsis. Also, Ghasemzadeh and Qureshi (2018) demonstrated that GRR value of $A$. swirskii was reduced from 8.62 to 3.83 and 5.95 offspring when mites were treated with fenpyroximate and thiaclopride, respectively. Nevertheless, several researchers found that some acaricides can stimulate mite fertility and fecundity. James (1997) stated that fecundity was increased when Amblyseius victoriensis was treated with imadoclopride. Also, Nadimi et al. (2008) found that the fecundityenhacing property of the acaricide hexythiazox to $P$. persimilis and therefore, he suggested this acaricide can make $P$. persimilis as an excellent choice as a biological control agent especially for crops growing in greenhouses.

Although the present data of the side effect of the novel acaricide cyflumetofen on $P$. persimilis agrees with some of the cited studies but also are somewhat different with others. Susceptibility between mite species and differences in experimental techniques could be the responsible for these conflicting results. Also, different values in life-table parameters reveal that acaricidal effect on the population strongly depend on the life history characteristics of spider mites or beneficial mite species and also on the chemical mode of actions.

\section{CONCLUSION}

All tested acricides showed a considerable toxicity to spider mite $T$. urticae but they didn't show the same killing action against the predatory mite. Cyflumetofen $\left(\mathrm{LC}_{50}\right)$ didn't have considerable effects on the fecundity and other population growth parameters of $P$. persimilis as compared with its effects on spider mites, therefore, it is recommended for use as a selective acaricides in IMM programs for spider mite in greenhouses. In other words, a selective acaricide is needed to adjust the prey/predator 
ratio and maintain long-term control. Further studies defining the specific effects of acaricide applications and residual exposure are important and necessary to evaluate compatibility of these compounds with augmentative and release of predaceous mite species that used in biological control. Also, the use of excessive chemical pesticide concentrations should be prevented.

\section{REFERENCES}

Abdel Rahman, H.R. and Fouly, A.H. (2001). Residual analysis of some pesticides in sweet pepper and their side effect on non-target mite species in greenhouses. J. Agric. Sci., Mansoura Univ., 26(1): 459-465.

Abbott, W.S. (1925). A method for computing the effectiveness of an insecticide. J. Econ. Entomol., 18: 265-267.

Abd El-Mageed, A.E.M, Tawfik, A.A. and Abohatab, E.E. (2013). Assessment of bioassay techniques and residual effect of certain acaricides against the twospotted spider mite, Tetranychus urticae Koch and the predatory mite, Phytoseiulus persimilis A.-H. Acarines, 7: 63-70.

Abou-Setta M.M., Sorrell, R.W. and Childers C.C. (1986). Life 48: a BASIC computer program to calculate life table parameters for an insect or mite species. Fla. Entomol. 69(4): 690-697

Birch, L. C. (1948). The intrinsic rate of natural increase of an insect population. J.Anim.Ecol., 17: 15 - 26.

Brandenburg, R. L. and Kennedy, G.G. (1987). Ecological and agricultural considerations in the management of two-spotted spider mite (Tetranychus urticae Koch). Agri. Zool. Rev. 2: 185-236.

Costat Software program (1990). Microcomputer program analysis, version 4.20, CoHort Software, Berkley, CA, USA. Doi:10.1016/j.biocontrol.2005.05.013

Dekeyser, M.A. (2005). Acaricide mode of action. Pest Mang. Sci., 61: 103-110.

Dekeyser, M.A., McDonald, P.T., Jr. Angle, G.W. and Moore, R.C. (1996). D-2341 - a novel agent to control spider mites. In: Proceedings, 1996 British Crop Protection Conference Pests and Diseases. British Crop Protection Council, Brighton, England: 487-492.

Finney, D.J. (1971). Probit analysis. A Statistical treatment of the sigmoid response curve. $7^{\text {th }}$ Ed., Cambridge Univ. Press, England.

Ghasemzadeh, S. and Qureshi, J. (2018). Demographic analysis of fenpyroximate and thiaclopride exposed predatory mite Amblyseius swirskii (Acar: Phytoseiida). Plos One: 15: 1-15. DOI: org/10.1371/ journal.pone.0206030.

Halloum, M. and Qerhaili, S. (2013). Comparative toxicity of some pesticides to Tetranychus urticae Koch and two phytoseiid mites. Acarines, 7: 57-61.

Hassan, S.A. (1992). Side effect tests for phytoseiids and their rearing methods. Meeting of the working group "Pesticides and Beneficial Organisms. IOBC| WPRS Bulletin, 15(3): 61-74.

Hayashi, N.; Sasama, Y.; Takahashi, N. and Ikemi, N. (2013). Cyflumetofen, a novel acaricide - its mode of action and selectivity. Pest Mang. Sci., 69: 10801084. Doi: $10.1002 /$ ps.3470
Helle, W. and Sabelis, M.W. (1985). Spider mites. Their biology, natural enemies and control. 1A. Elsevier, Amstrdam, 325s.

Henderson, C.F. and Tilton, E.W. (1955). Tests with acaricides against the brown wheat mite. J. Econ. Entomol., 48: 157-161. https://doi.org/10.1093/ jee/48.2.157

Hoy, M.A. (2011). Agricultural Acarology Introduction to Integrated Mite Management. International Standard Book Number: 978-1-4398-1751-3 (Hardback). http://www.taylorandfrancis.com.

Irigary, F., F.G. Zalom, F.G. (2006). Side effect of five new acaricides on thepredator Galendromus occidentalis (Acari: Phytoseiidae). Exp. Appl. Acarol., 38: 299305.

Irigary, F., Zalom, F.G. and Thompson, P.B. (2007). Residual toxicity of acaricides to Galendromus occidentalis and Phytoseiulus persimilis reproductive potential. Biological Control, 40: 153-159.

Isman, M. B., Miresmailli, S. and MacHial, C. (2011). Commercial opportunities for pesticides based on plant essential oils in agriculture, industry and consumer products. Phytochem. Rev. 10(2): 197204.

James, D.J. (1997). Imidaclopride increase egg production in Amblyseius victoriensis (Acari: Phytoseiidae). Exp. Appl. Acarol., 21: 75-82.

Kim, S.S and Seo, S.G. (2001). Relative toxicity of some acaricides to the predatory mite, Amblyseius womersleyi and the two-spotted spider mite, Tetranychus urticae (Acari: Phytaoseiidae :Tetranychidae). Appl. Entomol. Zool., 36: 509-514.

Kim, S.S. and Yoo, S.S. (2002). Comparative toxicity of some acaaricides to the predatory mite, Phytoseiulus persimilis and the two-spotted spider mite, Tetranychus urticae. BioControl, 47: 563-573.

Kim, S.K., Seo, S.G., Park, J.D. and Kim, D.I. (2005). Effect of selected pesticides on predatory mite, Amblyseius cucumeris (Acari: Phytoseiidae). J. Entomol. Sci., 40: 107-111.

Laing, J. E. (1968). Life history and life table of Phytoseiulus persimilis A.-H. Acarologia, 10: 578588.

Latheef, M.A and Hoffmann, W.C. (2014). Toxicity of Selected Acaricides in a Glass-vial Bioassay to Twospotted Spider Mite (Acari: Tetranychidae). Southwestern Entomologist, 39 (1): 29-36. Doi.org/10.3958/059.039.0104

Li, D., Tian, J. and Shen, Z. (2006). Assessment of sublethal effects of clofentezine on life - table parameters in hawthorn spider mite (Tetranychus viennsis). Exp. Appl. Acarol., 38: 255-273.

Marcic, D (2003). The effect of clofentezine on life-table parameters in two-spotted spider mite Tetranychus urticae. Exp. Appl. Acarol., 30: 249-263.

Marcic, D. (2007). Sublethal effects of spirodiclufen on life history and life-table parameters of two-spotted spider mite (Tetranychus urticae). Exp. Appl. Acarol., 42: 121-129.

McMurtry, J.A. and Croft, B.A. (1997). Life styles of phytoseiid mites and their roles as biological control agents. Ann. Rev. Entomol., 42: 291-321. 
Nadimi, A., Kamali, K., Arbabi, M. and Fateme Abdoli (2008). Side effects of three acaricides on the predatory mite, Phytoseiulus persimilis AthiasHenriot (Acari: Phytoseiidae) under laboratory conditions, Mun. Ent. Zool. 3 (2): 556-567.

Nadimi, A., Kamali, K., Arbabi, M. and Fateme Abdoli (2011). Study on persistence tests of miticides abamectin and fenproximate to predatory mite Phytoseiulus persimilis (Acarina"Phytoseiidae). African J. Agric. Res., 6(2): 338-342. Doi: 10.5897/AJAR09.411.

Poletti, M., Maia, A.H.N. and Omoto, C. (2007). Toxicity of neonicotinoid insecticides to Neoseiulus californicus and Phytoseiulus macropilis (Acari: Phytoseiidae) and their impact on functional response to Tetranychus urticae (Acari: Tetranychidae). Biological Control, 40: 30-36. Doi:10.1016/ j.biocontrol.2006.09.001

Ramasubramanian, T., Ramaraju, K. and Regupathy,A. (2005). Acaricide resistance in Tetranychus urticae Koch (Acari: Tetranychidae) - global scenario. J. Entomol.2: 33-39.

Rhodes, E.M., Oscar, E.L., Crystal, K., Silvia, I.R. and Roger, R.F. (2006). Comparison of single and combination treatments of Phytoseiulus persimilis, Neoseiulus californicus, and Acramite (bifenzate) for control of twospotted spider mites in strawberries. Exp. Appl. Acarol., 39: 213-225.

Sabelis, M.W. (1981). Biological control of two-spotted spider mites using phytoseiid predators. Part I: modelling the predator-prey interaction at the individual level. Pudoc, Wageningen: Agricultural Research Reports; p. 242.
Sabelis, M.W. (1985). Predator-prey interaction: predation on spider mite. In: Helle W, Sabelis MW, editors. World crop pests 1B. Spider mites: their biology natural enemies and control. Amsterdam: Elsevier; $p$. 103-129.

Sabelis, M.W. (1991). Life history evolution of spider mites. In: Schuster R and Murphy PW (eds): The Acari, reproduction, development and life history strategies. Chapman\& Hall, London: 23-49.

Samsøe-Petersen, L. (1983). Laboratory method for testing side effects of pesticides on juvenile stages of the predatory mite, Phytoseiulus persimilis (Acarina: Phytoseiidae) based on detached bean leaves. Entomophaga, 28: 167-178.

Tello, V., R. Vargas, Araya, J. and Cardemil, A. (2009). Biological parameters of Cydnodromus picanus and Phytoseiulus persimilis raised on the carmine spider mite, Tetranychus cinnabarinus (Acari: Phytoseiidae, Tetranychidae). Ciencia e Investigacion Agaria, 36 (2): 277-290.

Tirello, P., Pozzebon, A., Cassanelli, S., van Leeuwen, T. and Duso, C. (2012). Resistance to acaricides in Italian strains of Tetranychus urticae: toxicological and enzymatic assays. Exp. Appl. Acarol. 57(1): 5364.

Zhang, Z. Q. (2003). Mites of Greenhouses; Identification, Biology and Control. CABI Publishing. Wallingford. UK.

Zhang, Z. Q. and Sanderson, J. P. (1990). Relative toxicity of Abamectin to the predatory mite Phytoseiulus persimilis (Acari: Phytoseiidae) and two-spotted spider mite (Acari: Tetranychidae). J. Eco. Entomol., 83: $1783-1790$.

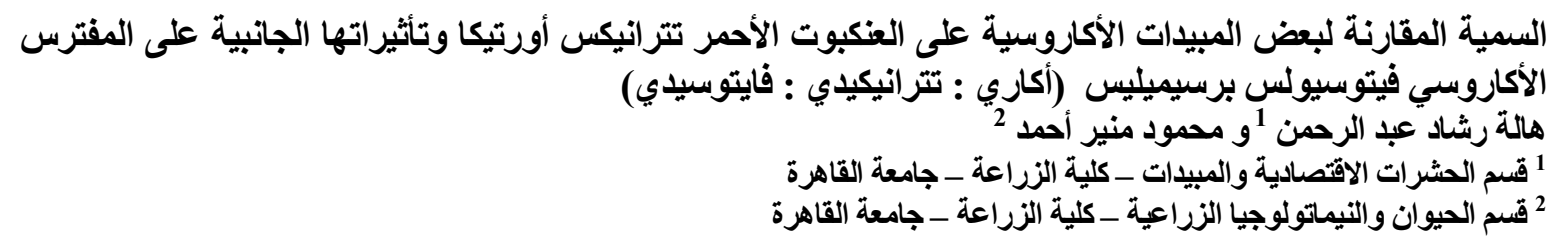

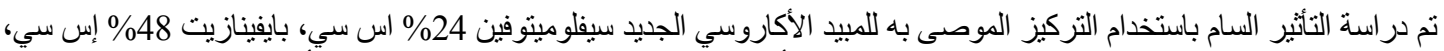

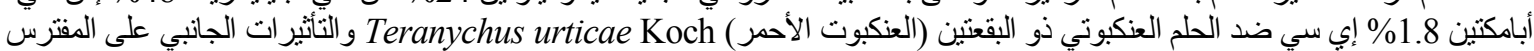

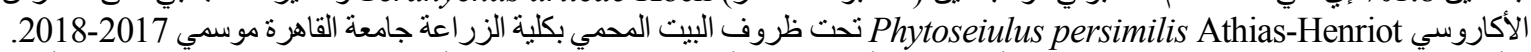

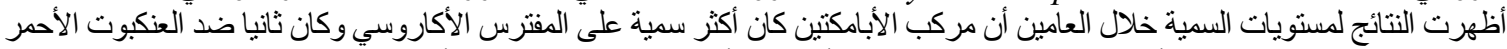

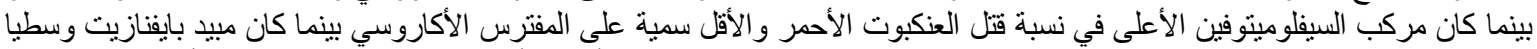

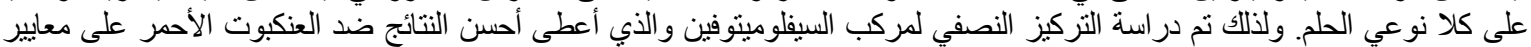

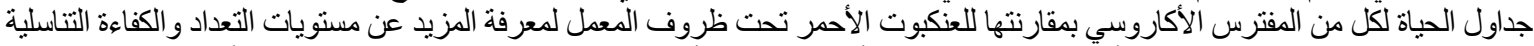

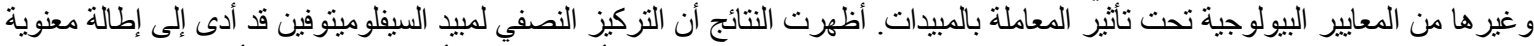

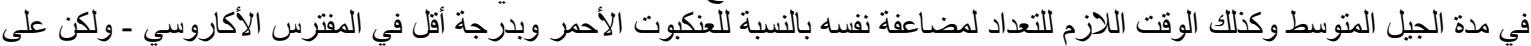

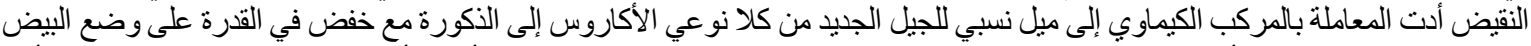

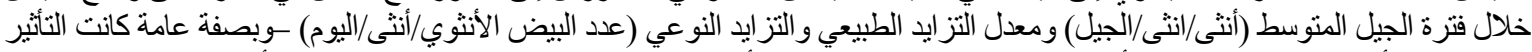

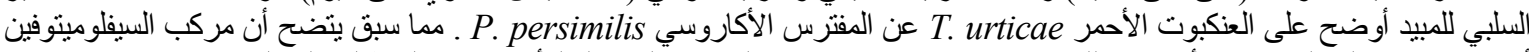
أكثر تخصصا على العنكبوت الأحمر وبذللك نوصي باستخدامه في برامج المكافحة المتكاملة للأكاروسات المتطفلة على النباتات. 